\title{
The Properties of RF Sputtered Zirconium Oxide Thin Films at Different Plasma Gas Ratio
}

\author{
Juyun Park, Jin Kook Heo, and Yong-Cheol Kang* \\ Department of Chemistry, Pukyong National University, Busan 608-737, Korea. *E-mail: yckang@pknu.ac.kr \\ Received December 6, 2009, Accepted December 29, 2009
}

\begin{abstract}
Zirconium oxide thin films deposited on the p-type $\mathrm{Si}(100)$ substrates by radio-frequency (RF) reactive magnetron sputtering with different plasma gas ratios have been studied by using spectroscopic ellipsometry (SE), atomic force microscopy (AFM), X-ray diffraction (XRD), and X-ray photoelectron spectroscopy (XPS). The deposition of the films was monitored by the oxygen gas ratio which has been increased from 0 to $80 \%$. We found that the thickness and roughness of the zirconium oxide thin films are relatively constant. The XRD revealed that the deposited thin films have polycrystalline phases, $\mathrm{Zr}(101)$ and monoclinic $\mathrm{ZrO}_{2}(\overline{1} 31)$. The XPS result showed that the oxidation states of zirconium suboxides were changed to zirconia form with increasing $\mathrm{O}_{2}$ gas ratio.
\end{abstract}

Key Words: RF sputtering, Zirconium oxide, Thin films, XPS

\section{Introduction}

Zirconium oxide thin films are of interest on account of their excellent properties such as large resistance against oxidation, low thermal conductivity, high dielectric constant, and high refractive index. This material has been employed as many applications, which include catalysts, ${ }^{1}$ optical filter, ${ }^{2}$ and resistive oxygen gas sensor. ${ }^{3}$ In addition, $\mathrm{ZrO}_{2}$ thin films have been considered to replace $\mathrm{SiO}_{2}$ due to their high $k$ dielectric property in the metal-oxide-semiconductor transistor. ${ }^{4}$ These applications have led to various techniques to synthesize zirconium oxide thin films including direct current reactive magnetron sputtering, ${ }^{5,6}$ chemical vapor deposition, ${ }^{7,8}$ sol-gel techniques, ${ }^{2,9}$ pulsed ion beam evaporation, ${ }^{10}$ liquid phase deposition, ${ }^{11}$ and filtered cathodic vacuum arc. ${ }^{12}$ Radio frequency (RF) reactive magnetron sputtering is a widely used technique which is affected by several deposition conditions, such as the RF power, mixing ratio of plasma gas, and substrate temperature etc. Ma et al..$^{13}$ have produced zirconium oxide thin films by RF reactive sputtering at different argon-oxygen atmosphere. They investigated the dielectric characteristics of the $\mathrm{ZrO}_{2}$ film. Gao group ${ }^{14}$ studied the influence of the $\mathrm{O}_{2}$ gas concentration on the optical properties, residual stress, and microstructure of the $\mathrm{ZrO}_{2}$ thin films. However, the chemical properties of the RF sputtered zirconium oxide thin films have been seldom reported. We studied the effects of the $\mathrm{O}_{2}$ ratio in the sputtering gas on the thickness, structure, and roughness of the deposited zirconium oxide thin films and oxidation state of elements in the films.

In the present work, we report the synthesis of zirconium oxide thin films by RF magnetron sputtering and the results of investigation into how the oxygen mixing ratio in the range of $0 \sim 80 \%$ affects physical and chemical properties of the zirconium oxide thin films. The chemical environment of the thin films was studied by means of X-ray photoelectron spectroscopy (XPS). Structural analysis of the zirconium oxide thin films was performed by atomic force microscopy (AFM) and X-ray diffraction (XRD) techniques. The thickness of film was investigated by spectroscopic ellipsometry (SE).

\section{Experimental Section}

Zirconium oxide thin films were deposited on p-type $\mathrm{Si}$ (100) wafer at room temperature using reactive RF (13.56 MHz) magnetron sputtering method in various oxygen mixing ratios. A zirconium target with a diameter of $50 \mathrm{~mm}$ was used for thin film deposition. The Si substrate was mounted on the sample holder located $58 \mathrm{~mm}$ from the target. The chamber was pumped down below $6.67 \times 10^{-5} \mathrm{~Pa}$ of base pressure, and the working pressure was kept constant about $6.07 \mathrm{~Pa}$. The argon and oxygen gases with purity of $99.999 \%$ fed into the vacuum chamber by standard mass flow controllers separately. The total flow rate was kept constant at $20 \mathrm{sccm}$, the oxygen mixing ratio in this work is calculated by the $\mathrm{O}_{2}$ flow rate divided by the total gas $\left(\mathrm{Ar}+\mathrm{O}_{2}\right)$ flow rate, and the values were varied between from 0 to $80 \%$. The deposition conditions applied in this study are summarized in Table 1.

The thickness of the zirconium oxide films was measured with the spectroscopic ellipsometry (SE) method. The morphology of the zirconium oxide thin films were checked with atomic force microscope (AFM, Veeco Multimode Digital Instruments Nanoscope III $\alpha$ system). The roughness of the films was measured as root mean square (rms) values. The XRD (PHILIPS (Netheland), X'Pert-MPD System) experiment was performed

Table 1. The deposition parameters for RF sputtered zirconium oxide thin films

$\begin{array}{ll}\text { Target } & \text { Zirconium } \\ \text { Substrate } & \mathrm{p}-\mathrm{Si}(100) \text { wafer } \\ \text { Sputtering pressure } & \sim 6.07 \mathrm{~Pa} \\ \text { Base pressure } & <6.67 \times 10^{-5} \mathrm{~Pa} \\ \text { Forward power } & 20 \mathrm{~W} \\ \text { Reflected power } & <4 \mathrm{~W} \\ \text { Substrate temperature } & \mathrm{Room} \text { temperature } \\ \text { Pre-sputtering time } & 1 \mathrm{hr} \\ \text { Sputtering time } & 3 \mathrm{hr}\end{array}$


for phase identification in glancing mode. Chemical property of the zirconium oxide films was studied with X-ray photoelectron spectroscopy (XPS, THERMO VG SCIENTFIC (UK), MultiLab2000), applying a monochromated $\mathrm{Al} \mathrm{K} \alpha$ X-ray source $(1486.6 \mathrm{eV})$. The survey XP spectra were obtained with a concentric hemispherical analyzer (CHA) in constant analyzer energy (CAE) mode with a pass energy of $50 \mathrm{eV}$ and an energy step size of $0.5 \mathrm{eV}$. High resolution XP spectra of $\mathrm{Zr} 3 \mathrm{~d}$ and $\mathrm{O}$ $1 \mathrm{~s}$ were obtained at a pass energy of $20 \mathrm{eV}$, an energy step size of $0.05 \mathrm{eV}$. The XP spectra of $\mathrm{Zr} 3 \mathrm{~d}$ and $\mathrm{O} 1 \mathrm{~s}$ were deconvoluted with XPSPEAK software (ver 4.1) in G/L ratio of $30 \%$ for the specific information of the oxidation states of the both elements and the ratios on the zirconium oxide films.

\section{Results and Discussion}

The thicknesses of deposited zirconium oxide thin films by RF magnetron sputtering were measured by spectroscopic ellipsometer as shown in Figure 1. This result is consistent with the previous investigation by Anderle's group that the deposition rate is affected by sputtering mixture ratio. ${ }^{15}$ In the plasma gas used to deposit zirconium oxide thin film, the argon ions are acted to sputter the zirconium particles from the target and the oxygen ions are acted as reactive species to form oxide. The sputtering yield is decreased, as the percentage of the oxygen gas is increased, especially this effect is severe when the oxygen concentration is above $73 \%{ }^{13}$ Therefore the thickness of zirconium oxide thin films is decreased with increasing $\mathrm{O}_{2}$ concentration in the mixed sputter gas in general. The thickness of the zirconium oxide thin films at the $20 \%$ of $\mathrm{O}_{2}$ gas was larger than other samples deposited in oxygen atmosphere. It could be caused by the loosely packed structure of the thin films. ${ }^{14}$

The microstructure and morphology of zirconium oxide thin films were investigated by AFM. Figure 2 gives AFM images of the zirconium oxide thin films in three-dimensional form with an area of $1 \times 1 \mu \mathrm{m}^{2}$. The morphologies of zirconium oxide thin films changed with increasing $\mathrm{O}_{2}$ ratio in the sputter gas. The grain size increased as the oxygen ratio increased. The rms (root mean square) roughness values, estimated from topographical images (not shown), are (a) 2.650, (b) 3.723, (c) 2.369, and (d) $2.897 \mathrm{~nm}$, respectively. When we compare the roughness of thin films made in 50 and $80 \%$ oxygen ratios, more granular zirconium oxide formed on the surface at $50 \% \mathrm{O}_{2}$ than at $80 \% \mathrm{O}_{2}$ shown in Figures 2 (c) and (d). This continuous granular grain lowers the roughness of the film. The role of sputter gas ratio was not significant on the roughness of thin film. However, at the $20 \%$ of $\mathrm{O}_{2}$ gas ratio, the surface roughness was larger than that of others. This may due to low packing density at $20 \%$ of oxygen gas ratio, and this phenomenon is reported that random packing structure can be observed in the samples which have a rough surface. $^{13,14}$

X-ray diffraction patterns of zirconium oxide thin films are shown in Figure 3. The notation of the samples is presented by $\mathrm{O}_{2}$-percentage. The crystalline $\mathrm{ZrO}_{2}$ generally can form monoclinic (m), tetragonal, cubic, or orthorhombic phase depending on the substrate temperature. ${ }^{16}$ The stable crystal structure is monoclinic phase zirconia at room temperature. In this study, two peaks were observed at about $38.5^{\circ}$ and $58.5^{\circ}$ of two theta, which

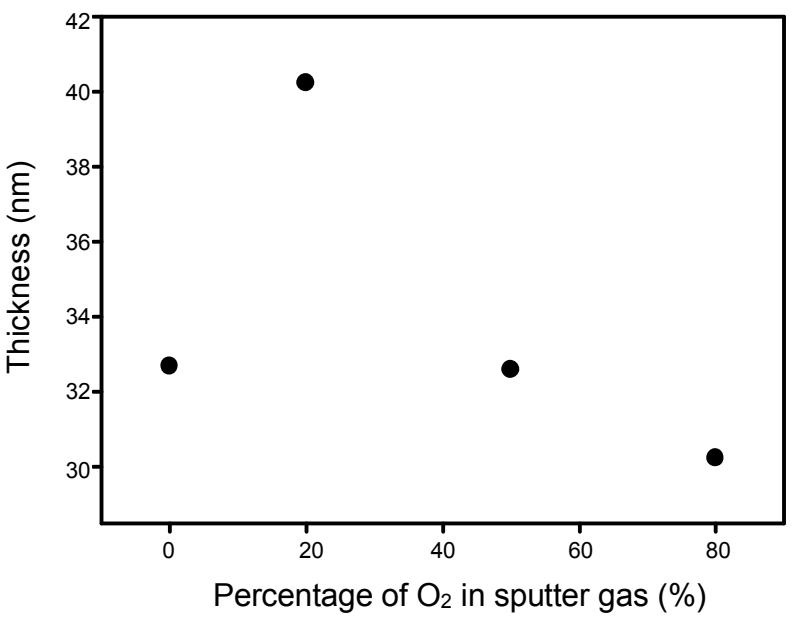

Figure 1. The thickness of the zirconium oxide thin films with different percentage of $\mathrm{O}_{2}$ in the sputter gas.
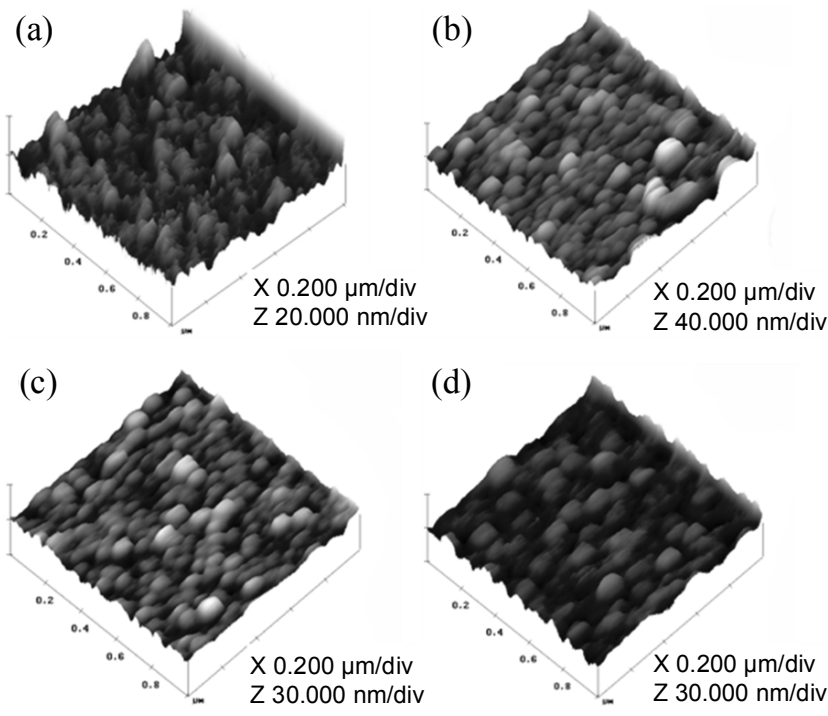

Figure 2. Representative AFM images of zirconium oxide on $\mathrm{Si}(100)$ substrate with different oxygen gas ratios: (a) $0 \%$; (b) $20 \%$; (c) $50 \%$; (d) $80 \%$.

correspond to (101) planes of $\alpha-\mathrm{Zr}$ single crystal $^{17}$ and $\mathrm{m}-\mathrm{ZrO}_{2}$ (131), respectively. ${ }^{18}$ The zirconium oxide thin films prepared by RF magnetron sputtering were polycrystalline phases, those were $\mathrm{Zr}$ single crystal and monoclinic zirconia. The relative intensity of $\mathrm{m}-\mathrm{ZrO}_{2}(\overline{131})$ is stronger than that of $\mathrm{Zr}(101)$ except when the $\mathrm{O}_{2}$ gas was zero. The dominant phase in the range above $20 \%$ of $\mathrm{O}_{2}$ gas concentration was the $\mathrm{m}-\mathrm{ZrO}_{2}(\overline{131})$. No remarkable change of intensity of $\mathrm{Zr}(101)$ peak were observed varying the $\mathrm{O}_{2}$ gas concentration. On the other hand, the crystallization of $\mathrm{m}-\mathrm{ZrO}_{2}(131)$ was dependent on the $\mathrm{O}_{2}$ concentration. As the concentration of $\mathrm{O}_{2}$ increased, monoclinic $\mathrm{ZrO}_{2}(\overline{131})$ phase was increased while crystalline metallic $\mathrm{Zr}$ was saturated at zero $\mathrm{O}_{2}$ concentration. ${ }^{19}$ The crystal sizes calculated by Scherrer equation from $\mathrm{m}-\mathrm{ZrO}_{2}(\overline{1} 31)$ peak were in the rage of $50 \mathrm{~nm}$. Therefore, the oxygen ratio in the sputter gas was an important role for formation of zirconium oxide thin film. 


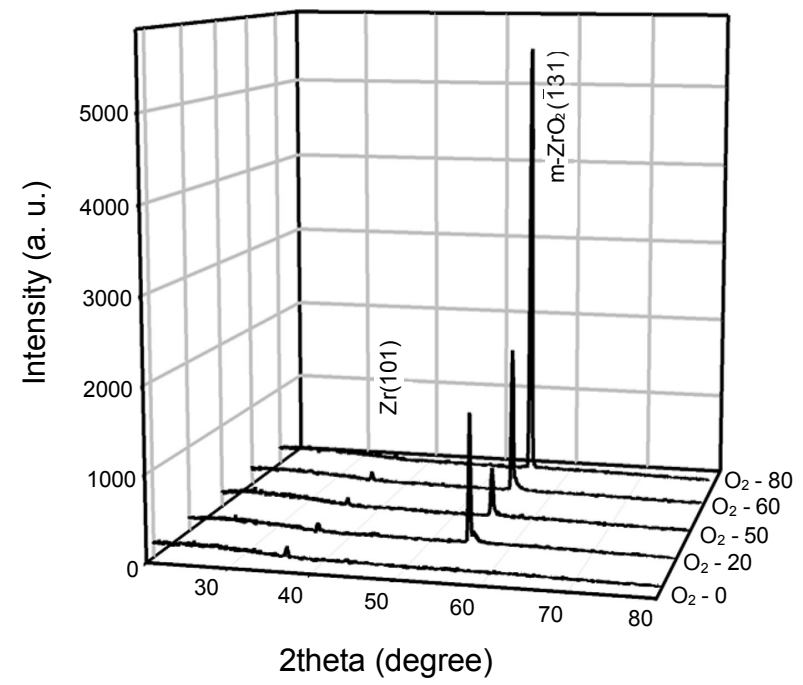

Figure 3. The XRD patterns of the zirconium oxide thin films on $\mathrm{Si}$ (100). The notation of the thin films is represented by $\mathrm{O}_{2}$-percentage.

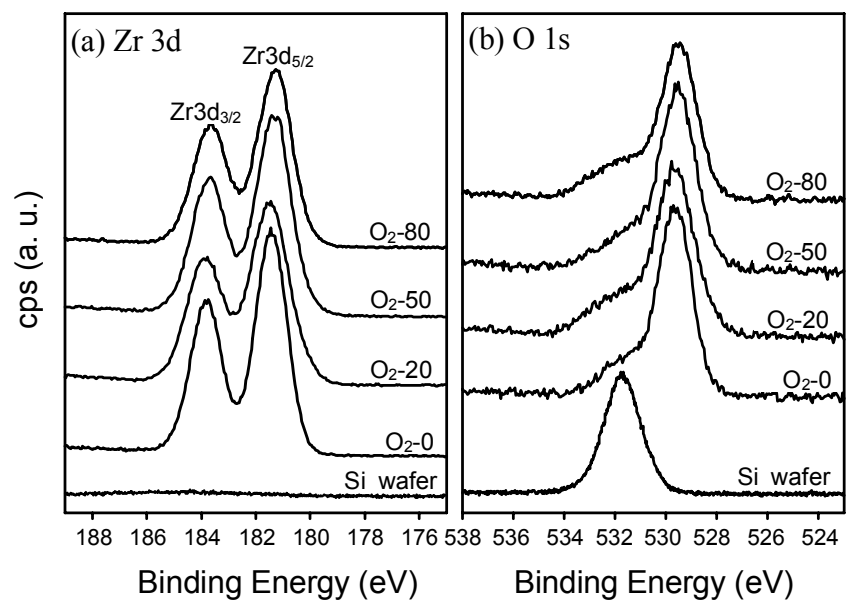

Figure 4. (a) $\mathrm{Zr} 3 \mathrm{~d}$ and (b) $\mathrm{O}$ 1s XP spectra of zirconium oxide thin films prepared at different $\mathrm{O}_{2}$ concentration.

Figures 4 (a) and (b) show the representative high resolution $\mathrm{XP}$ spectra of $\mathrm{Zr} 3 \mathrm{~d}$ and $\mathrm{O}$ 1s region of deposited zirconium oxide thin films with various $\mathrm{O}_{2}$ gas concentrations. Two peaks of $\mathrm{Zr} 3 \mathrm{~d}$ spectra correspond to the $\mathrm{Zr} 3 \mathrm{~d}_{5 / 2}$ and $\mathrm{Zr} 3 \mathrm{~d}_{3 / 2}$ with the spinorbit splitting of $2.4 \mathrm{eV} .^{20}$ The doublet $\mathrm{Zr} 3 \mathrm{~d}$ peaks of deposited zirconium oxide thin films were observed at 181.2 and 183.6 $\mathrm{eV}$ caused by bonding with oxygen. ${ }^{21}$ In Figure $4(\mathrm{~b})$, the $\mathrm{O} 1 \mathrm{~s}$ peak for O-Si $(531.7 \mathrm{eV})$ of zirconium oxide thin film coated on $\mathrm{Si}$ was dramatically decreased while that for $\mathrm{O}-\mathrm{Zr}(529.6 \mathrm{eV})$ was increased. And this was supported by XRD experiment shown in Figure 3. The comparison in FWHM (full width half maximum) of $\mathrm{Zr} 3 \mathrm{~d}$ peaks and $\mathrm{O} 1 \mathrm{~s}$ with different $\mathrm{O}_{2}$ gas concentration suggests that more than two oxidation states are existed. The $\mathrm{Zr} 3 \mathrm{~d}$ and $\mathrm{O} 1 \mathrm{~s}$ spectra are deconvoluted in order to understand further the chemical environment of zirconium oxide film and the effect of oxygen concentrations on the chemical environment of the zirconia thin films.

Figure 5 shows representative deconvoluted spectra of $\mathrm{Zr} 3 \mathrm{~d}$ and $\mathrm{O} 1 \mathrm{~s}$ regions. The dotted line represents raw data obtained
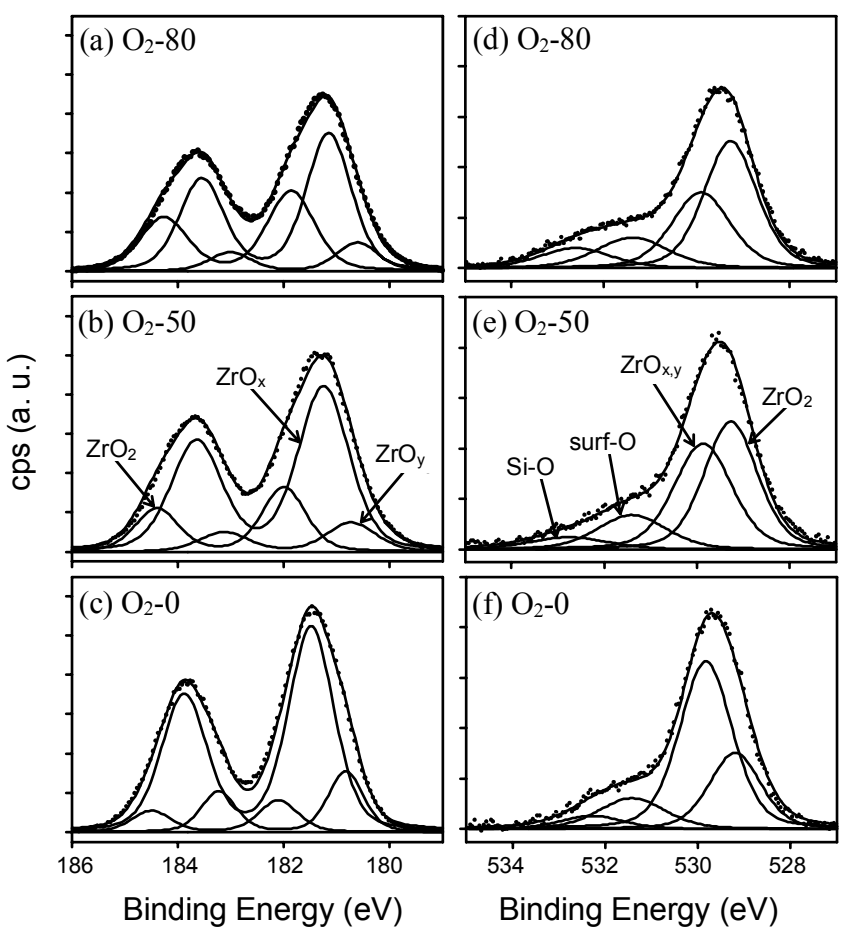

Figure 5. Deconvoluted XP spectra of $\mathrm{Zr} 3 \mathrm{~d}: \mathrm{O}_{2}-80$ (a), $\mathrm{O}_{2}-50$ (b), and $\mathrm{O}_{2}-0$ (c) and $\mathrm{O} 1 \mathrm{~s}: \mathrm{O}_{2}-80(\mathrm{~d}), \mathrm{O}_{2}-50(\mathrm{e})$, and $\mathrm{O}_{2}-0$ (f).

from XPS and the solid line overlapped with dotted line is the reconstructed data from the sum of individual peaks. In our study, three components are assigned in the $\mathrm{Zr} 3 \mathrm{~d}$ XP spectra. The formation of zirconium oxide was observed at the binding energy of $181.96 \mathrm{eV}$ for $\mathrm{Zr} \mathrm{3} \mathrm{d}_{5 / 2}$ which is very close to that of $\mathrm{Zr}^{4+}$ in $\mathrm{ZrO}_{2}{ }^{22}$ And the higher and lower oxidation states of zirconium suboxides $\left(\mathrm{ZrO}_{\mathrm{x}, \mathrm{y}} \mathrm{x}, \mathrm{y}<2 \text { and } \mathrm{x}>\mathrm{y}\right)^{23}$ were observed at 181.27 and $180.72 \mathrm{eV}$, respectively. The $\mathrm{ZrO}_{2}$ species was observed even at $0 \%$ oxygen sputter gas ratio. This oxide may be formed with the residual oxygen species $\left(\mathrm{O}_{2}, \mathrm{H}_{2} \mathrm{O}\right)$ inside the sputtering chamber. The $\mathrm{ZrO}_{2}$ peak intensity is increased by compensating from higher oxidation state $\left(\mathrm{ZrO}_{\mathrm{x}}\right)$ to zirconia as the $\mathrm{O}_{2}$ concentrations increased. Figures 5 (d)-(f) represent the deconvoluted spectra of $\mathrm{O} 1 \mathrm{~s}$. The $\mathrm{O} 1 \mathrm{~s}$ fitting was performed with four oxygen components, the dominant peak consists of two components which are $\mathrm{ZrO}_{2}$ at $529.24 \mathrm{eV}$ and zirconium suboxide $\left(\mathrm{ZrO}_{\mathrm{x}, \mathrm{y}}\right)$ at $529.84 \mathrm{eV}{ }^{22}$ The tail of the spectra contains chemisorbed $\mathrm{OH}$ groups (surf-O) and the oxygen bonded with $\mathrm{Si}(100)$ substrate (Si-O) at $531.43^{22}$ and $532.63 \mathrm{eV}$, respectively. The surface oxygen, which does not interact with zirconium, seems independent on the $\mathrm{O}_{2}$ concentration. On the other hand, the intensities of zirconium suboxides were decreased and that of $\mathrm{ZrO}_{2}$ was increased which is in good agreement with the data from deconvolution peaks of $\mathrm{Zr} 3 \mathrm{~d}$ spectra.

The relative amounts of different zirconium and oxygen species in the films were calculated with their peak areas considering atomic sensitivity factors to obtain more information shown in Figures 6 (a) and (b), respectively. The ratios of $\mathrm{Zr}$ and $\mathrm{O}$ species are quite different depending on the percentage of $\mathrm{O}_{2}$ in the sputter gas as mentioned previously. The higher oxidation states of zirconium oxide $\left(\mathrm{ZrO}_{\mathrm{x}}\right)$ was decreased from 72.5 to $55.6 \%$ with increasing $\mathrm{O}_{2}$ concentration and the zirconia form 


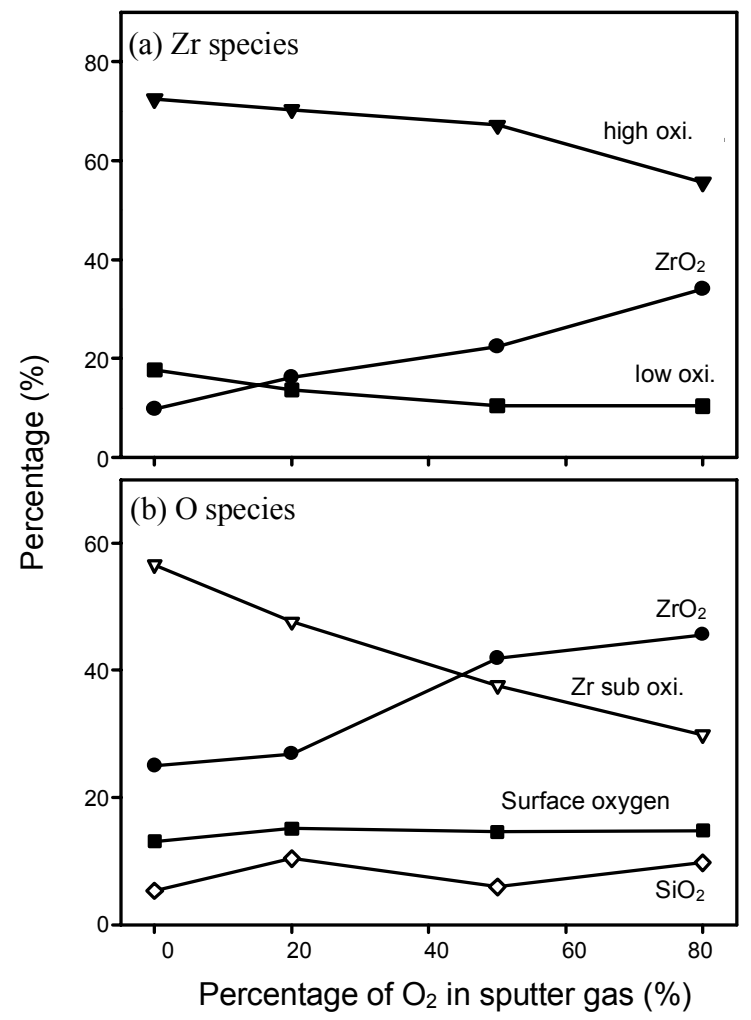

Figure 6. The relative ratios of (a) $\mathrm{Zr}$ species and (b) $\mathrm{O}$ species of different percentage of $\mathrm{O}_{2}$ in sputter gas.

was increased from 9.3 to $34 \%$ and the ratio of the lower oxidation states $\left(\mathrm{ZrO}_{\mathrm{y}}\right)$ at $80 \%$ of $\mathrm{O}_{2}$ in sputter gas was $7 \%$ less than that of $0 \%$ of $\mathrm{O}_{2}$ concentration. This implies that the higher oxidation state is easier to change zirconia form and has also been found in the study of the effect of different substrate temperatures on the zirconium oxide thin films. ${ }^{22}$ It could be explained by that the higher oxidation state needs less energies to transform into more stable zirconia state in monoclinic structure. Note that the ratios of oxygen species showed the same trend with $\mathrm{Zr}$ species.

\section{Conclusions}

Zirconium oxide thin films were deposited on the p-type $\mathrm{Si}(100)$ substrates by radio-frequency (RF) reactive magnetron sputtering with different plasma gas ratios. The monoclinic zirconium oxide thin film coexisted with $\mathrm{Zr}$ single crystal was obtained with mixed sputter gas, $\mathrm{Ar}$ and $\mathrm{O}_{2}$. The XP spectra showed that zirconium suboxide was oxidized to the zirconia as increasing $\mathrm{O}_{2}$ concentration. And the thickness of deposited thin film was in the range of $30 \sim 40 \mathrm{~nm}$ with varying $\mathrm{O}_{2}$ concentration. The surface roughness of the zirconium oxide thin films was relatively constant with the $\mathrm{O}_{2}$ gas ratio.

Acknowledgments. This work was supported by the Pukyong National University Research Fund in 2009 (PK-2009-19)

\section{References}

1. Miller, T. M.; Grassian, V. H. J. Am. Chem. Soc. 1995, 117, 10969.

2. Zhang, Q.; Li, X.; Shen, J.; Wu, G.; Wang, J.; Chen, L. Mater. Lett. 2000, 45,311 .

3. Izu, N.; Shin, W.; Matsubara, I.; Murayama, N.; Oh-hori, N.; Itou, M. Sens. Actuators B 2005, 108, 216.

4. Filipescu, M.; Scarisoreanu, N.; Craciun, V.; Mitu, B.; Purice, A.; Moldovan, A.; Ion, V.; Toma, O.; Dinescu, M. Appl. Surf. Sci. 2007, 253, 8184 .

5. Venkataraj, S.; Kappertz, O.; Liesch, C.; Detemple, R.; Jayavel, R.; Wuttig, M. Vacuum 2004, 75, 7.

6. Ji, Z.; Haynes, J. A.; Ferber, M. K.; Rigsbee, J. M. Surf. Coat. Technol. 2001, 135, 109.

7. Torres-Huerta, A. M.; Domínguez-Crespo, M. A.; Ramírez-Meneses, E.; Vargas-García, J. R. Appl. Surf. Sci. 2009, 255, 4792.

8. Komatsu, Y.; Sato, T.; Ito, S.; Akashi, K. Thin Solid Films 1999, $341,132$.

9. Brenier, R.; Mugnier, J.; Mirica, E. Appl. Surf. Sci. 1999, 143, 85.

10. Suematsu, H.; Kishi, T.; Inoue, J.; Hirai, M.; Suzuki, T.; Yunogami, T.; Jiang, W.; Yatsui, K. Mater. Lett. 2007, 61, 3635.

11. Lin, J. M.; Hsu, M. C.; Fung K. Z. J. Power Sources 2006, 159, 49.

12. Chua, D. H. C.; Milne, W. I.; Zhao, Z. W.; Tay, B. K.; Lau, S. P.; Carney, T.; White R. G. J. Non-Cryst. Solids 2003, 332, 185.

13. Ma, C. Y.; Lapostolle, F.; Briois, P.; Zhang, Q. Y. Appl. Suf. Sci. 2007, 253, 8718.

14. Gao, P.; Meng, L. J.; Santos, M. P.; Teixeira, V.; Andritschky, M. Vacuum 2000, 56, 143.

15. Gottardi, G.; Laidani, N.; Micheli, V.; Bartali, R.; Anderle, M. Surf. Coat. Technol. 2008, 202, 2332.

16. Koski, K.; Hölsä, J.; Juliet, P. Surf. Coat. Technol. 1999, 120-121, 303.

17. JCPDS Database, International Center for Diffraction Data. 2003, PDF 89-4902.

18. JCPDS Database, International Center for Diffraction Data. 2003, PDF 83-0944.

19. Wong, M. S.; Chia, W. J.; Yashar, P.; Schneider, J. M.; Sproul, W. D.; Barnett, S. A. Surf. Coat. Technol. 1996, 86-87, 381.

20. Matsuoka, M.; Isotani, S.; Sucasaire, W.; Kuratani, N.; Ogata, K. Surf. Coat. Technol. 2008, 202, 3129.

21. Tsunekawa, S.; Asami, K.; Ito, S.; Yashima, M.; Sugimoto, T. Appl. Surf. Sci. 2005, 252, 1651.

22. Chun, M. S.; Moon, M. J.; Park, J. Y.; Kang Y. C. Bull. Korean Chem. Soc. 2009, 30, 2729.

23. Yu, G. Q.; Tay, B. K.; Zhao, Z. W. Appl. Phys. A 2005, 81, 405. 